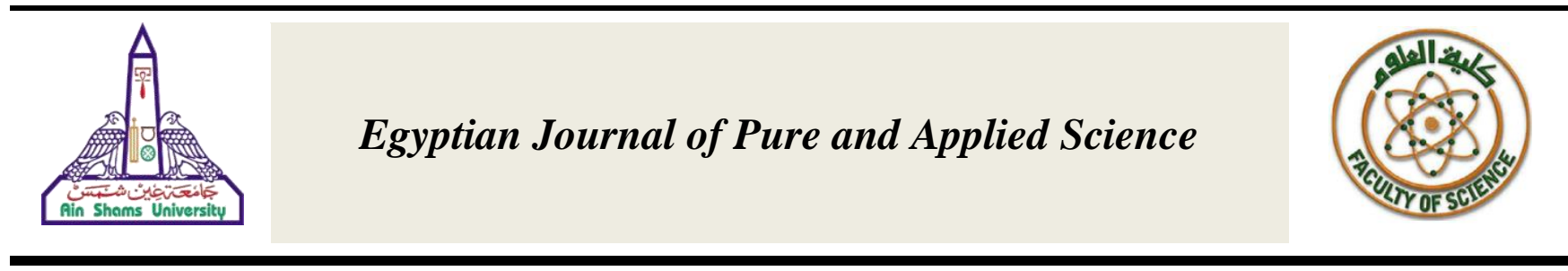

\title{
Role of rs 1800625 and 63bp deletion RAGE Gene Polymorphisms in Hepatocellular Carcinoma Progression
}

\author{
M. A. Mohammed ${ }^{1}$, A. A. Mohammed ${ }^{2}$, M. M. Mohammed ${ }^{1}$, M. G.A. Hegazy ${ }^{1}$ \\ ${ }^{1}$ Biochemistry department, Faculty of Science, Ain Shams University, Cairo, Egypt. \\ ${ }^{2}$ Medical Research Division, National Hepatology\& Tropical Medicine Research institute, Cairo, Egypt.
}

\section{ARTICLE INFO}

Received 20 June 2021

Accepted 13 October 2021

Keywords

Hepatocellular carcinoma,

Advanced glycation end product,

Single nucleotide polymorphism.

Correspondence

M. A. Mohammed

E-mail

maruomaaly@yahoo.com

\section{A BSTRACT}

Hepatocellular carcinoma (HCC) is a common liver malignancy, whose heterogeneous occurrence indicates genetic dissimilarities between people in the main risk factors. Advanced glycation end product receptor (RAGE) is a multiligand receptor implicated in several pathogenic conditions, including cancer. In this study, the impact of RAGE gene polymorphisms on the susceptibility to hepatocarcinogenesis was explored. To estimate the effect of gene variations of RAGE on the progress of HCC caused by any viral infection and to examine the relationship between a RAGE and the risk and progression of HCC. Single-nucleotide polymorphism (SNP; rs1800625) (-429T>C), and the 63 bp deletion (-407 to -345$)$ in the 5 ' flanking region of the RAGE gene were investigated among $90 \mathrm{HCV}$ patients divided into 3 groups and 20 healthy controls. The HCV cases were diagnosed by polymerase chain reaction (PCR) while the HCC was diagnosed by Alfa-fetoprotein (AFP) test in addition to computed tomography. Liver cirrhosis was diagnosed with abdominal sonography. The study detected a significant association of rs 1800625 with the increased risk of HCC also majority of HCC patient (86.7\%) showed $63 \mathrm{bp}$ deletion polymorphism (407 - 345), our data suggest a correlation of RAGE gene polymorphism rs 1800625 with the early stage of liver tumorigenesis and implicate its protective role in the progression of HCC.

\section{Introduction}

Hepatocellular carcinoma (HCC, also called malignant hepatoma) is the most common type of liver cancer ${ }^{[1]}$. It is the fifth most common neoplasm, the major cause of death in patients with cirrhosis, and the third most common cause of cancer-related death in the world ${ }^{[2]}$. HCC carcinogenesis is a complex process linked with various risk factors, counting exposure to aflatoxin $B$, hepatitis B virus or hepatitis C virus (HCV) (HBV) chronic infection, excessive alcohol and tobacco consumption, and diabetes ${ }^{[3]}$.

Egypt has the highest prevalence of HCV in the world (predominantly genotype 4 ), which has been attributed to previous public health eradication schemes for schistosomiasis ${ }^{[4]}$. Even higher HCV infection rates, up to $60 \%$, have been reported in older individuals, in rural areas such as the Nile delta, and in lower social classes ${ }^{[5]}$. In Egypt, HCC was reported to account for about $4.7 \%$ of CLD patients ${ }^{[6]}$. Between 1993 and 2002, there was an almost two-fold increase in HCC amongst chronic liver patients in Egypt ${ }^{[7]}$.

Several evidences have suggested that singlenucleotide polymorphisms (SNPs) may be linked to liver carcinogenesis in defined populations ${ }^{[8,9]}$. These studies spotlighted disparities within individual genomes that control oxidative stress, DNA repair, cell 
signaling, immune and inflammatory responses as genetic tendencies toward hepatic-tumorigenesis and somewhat clarified the detected differences in the risk of HCC incidence ${ }^{[10]}$.

Advanced glycation end products, known as AGEs, are substances that can be a factor in the development or worsening of many degenerative diseases, such as diabetes, atherosclerosis, chronic renal failure, and Alzheimer's disease. These harmful compounds can affect nearly every type of cell and molecule in the body and are thought to be one factor in aging and in some age-related chronic diseases.

Receptor for advanced glycation end products (RAGE) is a multiligand cell surface receptor that belongs to the immunoglobulin superfamily ${ }^{[11]}$. RAGE expression is usually low in the majority of healthy adult tissues, but its levels are elevated under pathological conditions such as diabetes, cardiovascular disease, Alzheimer's disease, and cancer ${ }^{[12,13]}$.

RAGE activation by various ligands have been reported to increase oxidative stress generation and subsequently evoke inflammatory, proliferative, angiogenic, fibrotic, thrombogenic, and apoptotic reactions in numerous cell types via activation of diverse intracellular signaling pathways such as nuclear factor-KB (NF-KB), mitogen-activated protein kinase (MAPK), Janus kinase-signal transducers and activators of transcription (JAK-STAT), and phosphoinositol 3 kinase [14, 15]. RAGE is expressed in hepatic cells, hepatocytes and hepatoma cells ${ }^{[16]}$. There is accumulating evidence that activation of RAGE signaling pathways in the liver could contribute to the development and progression of numerous types of hepatic disorders ${ }^{[17]}$.

Moreover, rs1800625 SNP of the RAGE gene has been shown to be widely linked with the progress of many malignancies, as lung, kidney, and oral cancers [18-20]. Also, 63 bp deletion; a rare variant; is known to increase the transcriptional activity of RAGE ${ }^{[21]}$.

We aimed in this study to evaluate the impact of gene variations of RAGE on the development of HCC caused by viral infection, and to observe a possible association of a RAGE SNPs with the risk and progression of HCC.

\section{Material and methods}

\subsection{Subjects}

The study was performed in the Research unit at Oncology Diagnostic Unit, Faculty of Medicine, Ain Shams University. The study was conducted on $90 \mathrm{HCV}$ patients divided into three groups:

Group I included $30 \mathrm{HCV}$ patients who developed Hepatocellular carcinoma (HCC). Group II included 30 HCV patients with liver cirrhosis. Group III: included 30 chronic HCV patients without cirrhosis, in addition 20 healthy individuals were enrolled as a control group (Group IV). Patients suffering from any other disease were omitted from our study as infection with Schistosomiasis or other endemic disease. An informed written consent was obtained from each individual and this study was approved by Ain Shams University, Faculty of Medicine Ethical Committee.

\subsection{Samples}

The blood samples were collected from patients attending Oncology Diagnostic Unit. The HCV cases were diagnosed by polymerase chain reaction (PCR) while the HCC ones were diagnosed by Alfa-fetoprotein (AFP) test in addition to computed tomography. Liver cirrhosis was diagnosed with abdominal sonography.

DNA was extracted from all patients and control groups using genomic peripheral mononuclear cells (PMNCs) blood extraction kit (Qiagen, Valencia, CA) according to the instructions of the manufacturer. All extracted DNA samples were stored at $-20^{\circ} \mathrm{C}$ and used as templates for Real-time (PCR).

\section{3 RAGE Genotyping}

The allelic discrimination of the RAGE SNPs was detected in all participants using the TaqMan assay for ( $r$ 1800625) $(-429 \mathrm{~T}>\mathrm{C}$ ) and the 63 bp deletion (-407 to -345) in the 5 'flanking region. Both were assessed using ABI StepOne TM Real-Time PCR System (Applied Biosystems) and analyzed using SDS v3.0 software (Applied Biosystems). rs1800625 was amplified using forward primer: 5'-CCTGGGTTTAGTTGAGAATTTTTT-3', reverse primer: 5'-ATTCATGCCTTTGGGA CAAGAG-3'. Real-time PCR reaction program for RAGE SNPS (rs1800625) was initial denaturation at $95^{\circ} \mathrm{C}$ for 10 minutes, followed by 40 cycles amplification (denaturation at $95^{\circ} \mathrm{C}$ for 15 seconds, annealing at $60^{\circ} \mathrm{C}$ for 30 seconds, elongation at $72^{\circ} \mathrm{C}$ for 30 seconds and finally $60^{\circ} \mathrm{C}$ for 1 minute). 
In addition, the $63 \mathrm{bp}$ deletion (-407 to -345) allelic polymorphisms detection ${ }^{[22]}$ was initiated at $94{ }^{\circ} \mathrm{C}$ for 1.5 minutes, then 35 cycles (denaturation at $95^{\circ} \mathrm{C}$ for 15 seconds, annealing at $60{ }^{\circ} \mathrm{C}$ for 30 seconds, elongation for 30 seconds at $72{ }^{\circ} \mathrm{C}$, and finally extension for 10 minutes at $72{ }^{\circ} \mathrm{C}$ ). The products were separated on a $3 \%$ agarose gel and then stained with ethidium bromide. $327 \mathrm{bp}$ and $390 \mathrm{bp}$ are the expected product sizes for the deleted and major allele, respectively.

\subsection{Statistical analysis}

Data were subjected to statistical analysis and tests of significance were performed using the statistical package SPSS (Statistical Program for Social Science) version 15.0 by applying Nonparametric tests (chi squared test and Fisher's exact probability test). The odds ratios (OR) and 95\% confidence intervals $(\mathrm{Cl})$ were also calculated. All $P$ values less than 0.05 by the twotailed test were considered significant. Variables that achieved statistical significance $(P<0.05)$ on univariate analysis were entered into multiple logistic regression analysis to identify significant independent predictive factors. Each variable was transformed into categorical data consisting of two simple ordinal numbers for univariate and multivariate analyses.

\section{Results}

\subsection{Demographic and clinical characteristics of the studied cases}

Among the present study, non-significant difference was observed in age among all studied group $(P>0.05)$. In the current study, a significant difference ( $P$-value: 0.001) was observed between the different studied groups considering patient's gender. Meanwhile, females predominate in group II, III, and control, they constitute approximately $80 \%$ of all subjects in the same group; males predominate in group I, they constitute19 (63.3\%) in contrast to $11(36.7 \%)$ for females Table 1.

Regarding, the subject's residence, a high significant difference was detected between the four participated groups Table 1. The majority of patients who develop HCC (group I) were of resident in rural areas $76.7 \%$, in contrast to 23.3 $\%$ who were of urban residence. In contrary, $60 \%$ and $66.7 \%$ of group II \& III patients respectively belong to urban origin. Likewise, urban residence predominates in the healthy control group, it constitutes $70 \%$. The smoking habits were reported and compared in different studied groups; no significant difference was observed between the four groups regarding smoking habits $(P>0.05)$ Table 1.

Table 1 Distribution of demographical characteristics in the studied groups

\begin{tabular}{|c|c|c|c|c|c|c|c|}
\hline \multirow[b]{2}{*}{ Variable } & \multirow[b]{2}{*}{ Subgroups } & \multicolumn{6}{|c|}{ Studied subjects } \\
\hline & & $\begin{array}{l}\text { Group I } \\
\mathrm{N}=30\end{array}$ & $\begin{array}{c}\text { Group II } \\
\mathrm{N}=30\end{array}$ & $\begin{array}{c}\text { Group III } \\
\mathrm{N}=30\end{array}$ & $\begin{array}{l}\text { Control } \\
\mathrm{N}=20\end{array}$ & $P$ - value & Sig. \\
\hline \multirow{2}{*}{ Age (years) } & Mean \pm SD & $60.1 \pm 6.8$ & $54.9 \pm 9.0$ & $52.2 \pm 9.0$ & $42.9 \pm 11.0$ & \multirow{2}{*}{0.072} & \multirow{2}{*}{ NS } \\
\hline & Range & $50.0-75.0$ & $39.0-68.0$ & $39.0-68.0$ & $17.0-57.0$ & & \\
\hline \multirow{2}{*}{ Gender N (\%) } & Male & $19(63.3 \%)$ & $6(20 \%)$ & 5 (16.7\%) & $4(20 \%)$ & \multirow{2}{*}{0.001} & \multirow{2}{*}{ HS } \\
\hline & Female & $11(36.7 \%)$ & $24(80 \%)$ & $25(83.3 \%)$ & $16(80 \%)$ & & \\
\hline \multirow{2}{*}{ Residence N (\%) } & Urban & 7 (23.3 \%) & $18(60 \%)$ & $20(66.7 \%)$ & $14(70 \%)$ & \multirow{2}{*}{0.001} & \multirow{2}{*}{ HS } \\
\hline & Rural & 23 (76.7 \%) & $12(40 \%)$ & $10(33.3 \%)$ & $6(30 \%)$ & & \\
\hline \multirow{2}{*}{ Smoking N (\%) } & Smoker & $6(20 \%)$ & 4 (13.3 \%) & $3(10 \%)$ & $2(10 \%)$ & \multirow{2}{*}{0.660} & \multirow{2}{*}{ NS } \\
\hline & Non-smoker & 24 (80 \%) & 26 (86.7 \%) & 27 (90 \%) & 18 (90 \%) & & \\
\hline
\end{tabular}

Group I: HCC/HCV positive; Group II: HCV positive with cirrhosis; Group III: HCV positive without cirrhosis 
3.2 Frequencies of RAGE (rs1800625) gene polymorphism among different studied groups

A cross-tabulation test was conducted to calculate the frequencies of distribution of RAGE gene polymorphism among the four studied groups. The majority of patients who developed HCC "group I" showed variant genotype (83.3\%), Also, the variant RAGE gene constitutes ( $80 \%),(73$ $\%)$ and (70 \%) in groups II, III, and control; respectively. Non-significant difference was detected between the four groups $(P>0.05)$. The distribution of RAGE gene genotype among the different studied groups is presented in Table 2.

\subsection{Frequencies of $63 \mathrm{bp}$ deletion (-407 to -345$)$ in the 5' flanking region RAGE gene polymorphism among different studied groups}

A cross-tabulation test was conducted to calculate the frequencies of the $63 \mathrm{bp}$ deletion $(-407-345)$ in the 5 ' flanking region of RAGE gene among the four studied groups. The results revealed that the $63 \mathrm{bp}$ deletion was detected in 63 cases ( 55 patients out of 90 and 8 in control group out of 20) and that the majority of patients who developed HCC "group I" showed variable genotype $(87.7 \%)$. In addition, the variant RAGE gene constitutes (67.7 \%), (30\%) and (40\%) in-group II, III, control respectively. A high significant difference was detected between the four groups $(P<0.001)$. The distribution of $63 \mathrm{bp}$ deletion of RAGE gene among the different studied groups is presented in Table 3 .

Table 2 Genotype Frequencies of RAGE (rs; 1800625) Gene Polymorphisms the studied subjects

\begin{tabular}{|c|c|c|c|c|c|c|c|}
\hline Variable & $\begin{array}{l}\text { Group I } \\
\mathrm{N}=30\end{array}$ & $\begin{array}{c}\text { Group II } \\
N=30\end{array}$ & $\begin{array}{c}\text { Group III } \\
\mathrm{N}=30\end{array}$ & $\begin{array}{l}\text { Control } \\
\mathrm{N}=20\end{array}$ & $c^{2^{*}}$ & $P$ - value & Sig \\
\hline Wild, N (\%) & $5(16.7 \%)$ & $6(20 \%)$ & $8(26.7 \%)$ & $6(30 \%)$ & \multirow{2}{*}{1.622} & \multirow{2}{*}{0.654} & \multirow{2}{*}{ NS } \\
\hline Variant, N (\%) & 25 (83.3 \%) & $24(80 \%)$ & 22 (73.3 \%) & $14(70 \%)$ & & & \\
\hline
\end{tabular}

Table 3 Genotype Frequencies 63bp deletion of RAGE Gene among different studied subjects

\begin{tabular}{|c|c|c|c|c|c|c|c|}
\hline Variable & $\begin{array}{l}\text { Group I } \\
\mathrm{N}=30\end{array}$ & $\begin{array}{c}\text { Group II } \\
N=30\end{array}$ & $\begin{array}{c}\text { Group III } \\
N=30\end{array}$ & $\begin{array}{l}\text { Control } \\
N=20\end{array}$ & $\mathrm{c}^{2^{*}}$ & $P$-value & Sig \\
\hline Wild, N (\%) & 4 (13.3 \%) & 10 (33.3 \%) & 21 (70 \%) & $12(60 \%)$ & \multirow{2}{*}{23.2} & \multirow{2}{*}{0.000} & \multirow{2}{*}{ HS } \\
\hline DEL, N (\%) & 26 (87.7 \%) & 20 (67.7 \%) & 9 (30 \%) & 8 (40 \%) & & & \\
\hline
\end{tabular}

${ }^{*}$ Chi-square test $\mathrm{HS}$ : high significant difference $(\mathrm{p}<0.01)$

Group I: HCC/HCV positive; Group II: HCV positive with cirrhosis; Group III: HCV positive without cirrhosis

3.4 Genotype Distribution of RAGE gene (T/C; rs1800625) polymorphism among different studied groups

In order to determine the predominant genotype of RAGE gene $(T / C)$ polymorphism, we calculated the frequencies of different genotypes among the four investigated groups, the results revealed that the heterozygous TC genotype was the most frequent $(56 \%)$ in the chronic HCV patients who develop $\mathrm{HCC}$ (group I), followed by the homozygous TT genotype which constitutes $32 \%$. Likewise, $58 \%$ \& $73 \%$ of group II \& III respectively showed predominant heterozygous TC genotype. For the healthy control, $50 \%$ of subjects showed homozygous TT genotype, followed by $43 \%$ of heterozygous TC genotype, however, the homozygous CC genotype was observed in one subject only. The distribution of T/C gene polymorphism of RAGE gene among the four studied groups is presented in Table 4. 
M. A. Mohammed et al /Egy. J. Pure \& Appl. Sci. 2021; 59(1):20-28

Table 4 Genotype Distribution of RAGE rs 1800625 Gene Polymorphisms in the studied subjects

\begin{tabular}{lccccccc}
\hline \multirow{2}{*}{ Variable } & Total & Group I & Group II & Group II & Control & \multirow{2}{*}{$\mathrm{c}^{2}$} & \multirow{2}{*}{ - value } \\
& $\mathrm{N}(\%)$ & $\mathrm{N}=30$ & $\mathrm{~N}=30$ & $\mathrm{~N}=30$ & $\mathrm{~N}=20$ & & \\
\hline TT & $26(30.5 \%)$ & $8(32 \%)$ & $5(21 \%)$ & $6(27 \%)$ & $7(50 \%)$ & & \multirow{2}{*}{0.183} \\
TC & $50(59 \%)$ & $14(56 \%)$ & $14(58 \%)$ & $16(73 \%)$ & $6(43 \%)$ & 8.8 & \\
CC & $9(10.5 \%)$ & $3(12 \%)$ & $5(21 \%)$ & $0(0 \%)$ & $1(7 \%)$ & & \\
Total variant & 85 & 25 & 24 & 22 & 14 & \\
\hline
\end{tabular}

${ }^{*}$ Chi-square test NS: Non-significant difference $(P>0.05)$

Group I: HCC/HCV positive; Group II: HCV positive with cirrhosis; Group III: HCV positive without cirrhosis

\subsection{Genotype Distributions of RAGE 63bp deletion among different studied groups}

A cross-tabulation test was conducted; the $63 \mathrm{bp}$ deletion was detected in 46 subjects (73\%) among 63. Our data also reveal that $85 \%$ of RAGE gene polymorphism observed in group I, are of deletion genotype (22 out of 26), likewise, $75 \%$ (15 out of 20) and $67 \%$ (6 out of 9) deletions were observed in group II and group III, respectively. In contrast, it was found that the $63 \mathrm{bp}$ deletion was less frequently distributed among healthy control group $(3 / 8 ; 38 \%)$. Our results showed that, there was no significant difference between the different studied groups as regarding the type of 63bp RAGE gene deletion polymorphism $(P>0.05)$ Table 5.

\subsection{Association between RAGE (T/C rs1800625) gene polymorphism and liver status}

A normality test was performed for the serum levels of AFP, AST and ALT in all groups. Higher median levels of AFP and AST were observed in patient who had TT genotype in contrast to non-TT genotype, $(P>0.05)$. On the other hand, the non- $T$ genotype showed higher serum level of ALT in contrast to the TT genotype. These data are presented in Table 6.

Table 5 Genotype Distributions of RAGE 63bp deletion in the studied subjects

\begin{tabular}{lcccccccc}
\hline Variable & Total & Group I & Group II & Group III & Control & $c^{2}$ & $P$ - value & Sig \\
\hline $63 \mathrm{bp} \mathrm{del}$ & $46(73 \%)$ & $22(85 \%)$ & $15(75 \%)$ & $6(67 \%)$ & $3(38 \%)$ & 7.1 & 0.06 & NS \\
\hline
\end{tabular}

$\mathrm{X}^{2}$ * ${ }^{*}$ Chi-square test $\quad$ NS: Non-significant difference $(P>0.05)$

Group I: HCC/HCV positive; Group II: HCV positive with cirrhosis; Group III: HCV positive without cirrhosis

Table 6 Association of RAGE Genotypic Frequencies with HCC Laboratory Status

\begin{tabular}{lccccc}
\hline Variable & TT (Wild type) & TC/CC (Variant type) & \multirow{2}{*}{$\mathrm{c}^{2}$} & $P$-value & Sig \\
\hline AFP $(\mathrm{ng} / \mathrm{ml})$ & $\mathrm{N}=26$ & $\mathrm{~N}=59$ & & & \\
AST $(\mathrm{IU} / \mathrm{ml})$ & $115(8.2-4900)$ & $28(3.3-5000)$ & 1.5 & 0.2 & NS \\
ALT $(\mathrm{IU} / \mathrm{ml})$ & $79(36-141)$ & $40(15-92)$ & 3.4 & 0.06 & NS \\
\hline${ }^{*}$ Chi-square test & NS: Non-significant difference $(P>0.05)$ & $47(13-114)$ & 2.2 & 0.14 & NS \\
\hline
\end{tabular}

*Chi-square test NS: Non-significant difference $(P>0.05)$

\subsection{Associations between RAGE (T/C rs1800625)} Genotypes and Clinicopathologic characteristics of $\mathrm{HCC}$

In order to determine the impact of $C / T$ RAGE gene polymorphisms detected in group $I$ on the severity of HCC in chronic HCV infected patients, we compared the frequencies of TT and non-TT (TC/CC) genotypes in risk groups of $\mathrm{HCC} / \mathrm{HCV}$ positive using log regression analysis. Our results revealed that, there was nosignificant difference between both genotypes regarding gender (OR: 0.9), Lymph nodes metastases (OR: 2.2), and Barcelona clinic liver cancer (BCLC) score (OR: 1.1). These data are presented in Table 7. 
Table 7 Associations between Polymorphic Genotypes of rs1800625 and Clinico-pathologic characteristics of $\mathrm{HCC} / \mathrm{HCV}$ positive group

\begin{tabular}{|c|c|c|c|c|c|c|}
\hline \multirow{3}{*}{ Parameter } & \multirow{3}{*}{ Subgroups } & \multicolumn{2}{|c|}{ RAGE rs1800625 } & \multicolumn{2}{|c|}{ Statistics } & \multirow{3}{*}{ Sig } \\
\hline & & TT & $\mathrm{TC}+\mathrm{CC}$ & Odd ratio & $P$ value & \\
\hline & & $N=8$ & $N=17$ & & & \\
\hline \multirow[t]{2}{*}{ Gender } & Male & $5(31 \%)$ & 11 (69 \%) & \multirow{2}{*}{$0.9(0.2-6.0)$} & \multirow{2}{*}{0.91} & \multirow{2}{*}{ NS } \\
\hline & Females & $3(33 \%)$ & $6(67 \%)$ & & & \\
\hline \multirow[t]{2}{*}{ LN metastases } & No & 7 (31 \%) & $16(69 \%)$ & \multirow{2}{*}{$2.2(0.1-42)$} & \multirow{2}{*}{0.56} & \multirow{2}{*}{ NS } \\
\hline & Yes & 1 (50 \%) & $1(50 \%)$ & & & \\
\hline \multirow[t]{2}{*}{ BLCL score } & $A$ & 4 (33 \%) & $8(67 \%)$ & \multirow{2}{*}{$1.1(0.2-6.0)$} & \multirow{2}{*}{0.17} & \multirow{2}{*}{ NS } \\
\hline & $B+C$ & $4(31 \%)$ & 9 (69 \%) & & & \\
\hline
\end{tabular}

LN: lymph nodes, BLCL: Barcelona clinic liver cancer $(B C L C)$ staging, A: Early stage, B: Intermediate Stage, C: Advanced stage, HCV: Hepatitis C Virus

\section{Discussion}

According to the Egyptian Demographic Health Survey (EDHS) registry, Egypt is the country which recorded the highest HCV prevalence in the world at $2008{ }^{[23]}$. HCC represent the $2^{\text {nd }}$ common malignancy, this was contributed to the underlying chronic liver disease especially the viral infection, which include Hepatitis C virus (HCV) and Hepatitis B Virus (HBV) ${ }^{[24]}$.

Genetic mutations reflect the heterogeneous variations among individuals in the main risk factors, this means that in spite of the carcinogenic predisposition of chronic HCV, the development of HCC in those patients is highly influenced by their genetic predisposition, which further increase the risk in those patients ${ }^{[25]}$.

The receptor for advanced glycosylation endproducts (RAGE) is a multi-ligand receptor which has been implicated in the development or worsening of many degenerative diseases, such as atherosclerosis, chronic renal failure, auto-immune diseases, diabetes, cancer, inflammatory disorders and Alzheimer disease. These harmful compounds can affect nearly every type of cell and molecule in the body and are thought to be one factor in aging and in some age-related chronic diseases ${ }^{[26]}$.

In this study, the impact of RAGE gene polymorphisms on the susceptibility to develop HCC in Egyptian patients with chronic HCV infection was investigated, in addition, the association between the RAGE gene mutation and prognosis of HCC has been evaluated. All participants were examined for the RAGE (C/T) rs: 1800625 genotype, moreover, the $60 \mathrm{bp}$ deletion allele (-407 to -345$)$ polymorphism was determined in all subjects in the 5 ' flanking region of RAGE gene, and the impact of RAGE gene polymorphisms on the development of HCC in chronic HCV patients was analyzed.

In the current study, no-significant association was detected between the four studied groups regarding the heterogeneity in RAGE gene polymorphism. However, the highest frequency of RAGE gene polymorphism was detected in the chronic HCV patients who developed HCC, variant genotype was detected in $83.3 \%$ of patients in contrast to $16.7 \%$ who showed wild type of RAGE gene.

These finding agreed with Shih-Chi et al. ${ }^{[27]}$ who showed a significant correlation of RAGE gene $\mathrm{C} / \mathrm{T}$ (rs1800625) polymorphism with liver carcinogenesis, also, it was reported that it has a protective role in the progression of HCC. In consistent with our results, Shih-Chi et al. [27] found a significant association between the RAGE gene rs 1800625 polymorphism and the increase in risk to HCC when compared to control group.

It has been reported that the $\mathrm{rs} 1800625 \mathrm{C} / \mathrm{T}$ polymorphism form of RAGE gene is significantly associated with the development of different types of cancers including, renal, oral ${ }^{[28]}$, lung ${ }^{[28]}$ and liver cancer [29]. In addition to its carcinogenic effect, it has been demonstrated that many RAGE gene polymorphisms are significantly associated with cancer progression ${ }^{[30]}$.

However, previous study failed to demonstrate a significant association between the rs 1800625 RAGE 
gene polymorphism and increased risk to breast cancer ${ }^{[30]}$. These cumulative data suggest that many forms of genetic heterogeneity have been implicated in different types of cancers. Although different tumors may share the same risk allele, they have different tumorigenic potential.

RAGE is expressed in hepatic cells, hepatocytes and hepatoma cells ${ }^{\left[{ }^{[1]}\right.}$ There is accumulating evidence that activation of RAGE signaling pathways in the liver could contribute to the development and progression of numerous types of hepatic disorders ${ }^{[32]}$. The RAGE signaling pathways have been influenced by numerous RAGE isoforms. Under certain conditions, these signaling pathways are generated by the alternative processing of mRNAs or through a full proteolytic breakdown of the full-length RAGE gene ${ }^{[32]}$.

In order to determine the impact of $\mathrm{C} / \mathrm{T}$ RAGE (rs1800625) gene polymorphism on the severity of $\mathrm{HCC}$ in chronic HCV infected patients, we compared the frequencies of TT and non-TT (TC/CC) genotypes in different risk groups of HCC using log regression analysis. Our results revealed that, there was nosignificant difference between both genotypes regarding gender, $\mathrm{LN}$ metastases, and BCLC score.

Our results revealed that the heterozygous TC genotype was the most frequent (56\%) in the HCC group when compared with other genotypes (TT\&CC). Shih-Chi et al. [27], found TT genotype was the most frequent in HCC patients. Moreover, the functional impact of rs1800625 genotype on progression of HCC has been demonstrated in previous studies, they reported that an alternation in RAGE expression positively promotes tumorigenesis in liver cells and negatively regulates the progression of $\mathrm{HCC}{ }^{[33]}$.

In the present study, we determined the frequencies of the 63bp deletion polymorphism (-407-345) in the 5' flanking region of RAGE gene among the four studied groups. We detected a high significant difference between the four groups regarding the distribution of $63 \mathrm{bp}$ deletion of RAGE gene among them.

The results revealed that the majority of patients who developed HCC "group I" showed non-wild genotype $86.7 \%$ in contrast to $13 \%$ who showed wild type of RAGE gene. Also, we observed higher non-wild genotype in patients with liver cirrhosis "group II" than wild genotype. In agreement with our results, it has been reported that the $63 \mathrm{bp}$ deletion allele (-407-345) is widely associated with different types of malignancies. Moreover, it has been demonstrated that the $63 \mathrm{bp}$ deletion variant has a great impact on RAGE expression, therefore, it is significantly implicated in early hepatocarcinogenesis. Therefore, once HCC develops, the RAGE gene expression starts to decline with the increase in tumor growth and progression ${ }^{[34]}$.

In addition, we also explored the potential association between the RAGE gene polymorphisms and the levels of several serum markers of HCC, including a fetoprotein, alanine transaminase, and aspartate transaminase. As a consequence, no significant difference in the serum levels of these markers was detected between patients who possess at least 1 polymorphic allele and those who do not for any of the RAGE SNPs examined

\section{Conclusion}

The current study demonstrated that the RAGE gene polymorphism (63bp deletion) significantly contributed to development of HCC in chronic HCV patients while this contribution was non-significant in rs1800625; however, it is not associated with HCC progression. Accordingly, our data indicated the impact of RAGE gene variations on HCC development in HCV infected patients. Taken together, our results showed that SNP 63bp deletion was frequently distributed among HCC patients which could contribute to an increased risk of HCC. These findings indicate a novel genetic predisposition to liver tumorigenesis.

\section{References}

1. El-Serag, H. B. (2012). Epidemiology of viral hepatitis and hepatocellular carcinoma. Gastroenterology, 142: 1264 - 1273.e1 [PMID: 22537432 DOI: 10.1053/j.gastro.2011.12.061]

2. Lovet, J. M., Burroughs, A. and Bruix, J. (2003). Hepatocellular carcinoma. Lancet, 362: 1907-1917.

3. Forner, A., Lovet, J. M. and Bruix, J. (2012). Hepatocellular carcinoma. Lancet, 379: 1245-1255.

4. Strickland, G. T. (2006). Liver disease in Egypt: hepatitis $C$ superseded schistosomiasis as a result of iatrogenic and biological factors. Hepatology, 43: 915 $-922$. 
5. Hassan, M. M., Zaghloul, A. S., El-Serag, H. B. and et al. (2001). The role of hepatitis $C$ in hepatocellular carcinoma: a case control study among Egyptian patients. J. Clin. Gastroenterol, 33: $123-126$.

6. El-Zayadi, A. R., Abaza, H., Shawky, S. and et al. (2001). Prevalence and epidemiological features of hepatocellular carcinoma in Egypta single center experience. Hepatol. Res., 19: $170-179$.

7. El-Zayadi, A. R., Badran, H. M., Barakat, E. M. and et al. (2005). Hepatocellular carcinoma in Egypt: a single center study over a decade. World J. Gastroenterol., 11: 5193 - 5198.

8. Miki, D., Ochi, H., Hayes, C. N. and et al. (2012). Hepatocellular carcinoma: towards personalized medicine. Cancer Sci., 103: 846 850.

9. Jin, F., Xiong, W. J., Jing, J. C. and et al. (2011). Evaluation of the association studies of single nucleotide polymorphisms and hepatocellular carcinoma: a systematic review. J. Cancer Res. Clin. Oncol., 137: 1095 1104.

10. Nahon, P. and Zucman-Rossi, J. (2012). Single nucleotide polymorphisms and risk of hepatocellular carcinoma in cirrhosis. J. Hepatol., 57: $663-674$.

11. Ramasamy, R., Yan, S. F. and Schmidt, A. M. (2012). The diverse ligand repertoire of the receptor for advanced glycation endproducts and pathways to the complications of diabetes. Vascul. Pharmacol., 57: 160- 167.

12. Sorci, G., Riuzzi, F., Giambanco, I. and Donato, R. (2013). RAGE in tissue homeostasis, repair and regeneration. Biochim. Biophys. Acta., 1833: $101-109$.

13. Takeuchi, M. and Yamagishi, S. (2009). Involvement of toxic AGEs (TAGE) in the pathogenesis of diabetic vascular complications and Alzheimer's disease. J/ Alzheimers Dis., 16: 845 - 858.

14. Daffu, G., Del Pozo, C. H., O'Shea, K. M., Ananthakrishnan, R., Ramasamy, R. and Schmidt, A. M. (2013). Radical roles for RAGE in the pathogenesis of oxidative stress in cardiovascular diseases and beyond. Int. J. Mol. Sci., 14: 19891 - 19910.
15. Ott, C., Jacobs, K., Haucke, E., Navarrete, Santos, A., Grune, T. and Simm, A. (2014). Role of advanced glycation end products in cellular signaling. Redox Biol., 2: $411-429$.

16. Hyogo, H. and Yamagishi, S. (2008). Advanced glycation end products (AGEs) and their involvement in liver disease. Curr. Pharm. Des., 14: $969-972$

17. Basta, G., Navarra, T., De Simone, P., Del Turco, S., Gastaldelli, A. and Filipponi, F. (2011). What is the role of the receptor for advanced glycation end products-ligand axis in liver injury? Liver Transpl., 17: 633 - 640.

18. Pan, H., Niu, W., He, L. and et al. (2013). Contributory role of five common polymorphisms of RAGE and APE1 genes in lung cancer among Han Chinese. PloS One, 8: e69018.

19. Su, S., Chien, M., Lin, C. and et al. (2015). RAGE gene polymorphism and environmental factor in the risk of oral cancer. J. Dent. Res., 94: $403-411$.

20. Chocholaty, M., Jachymova, M., Schmidt, M. abd et al. (2015). Polymorphisms of the receptor for advanced glycation end-products and glyoxalase $\mathrm{I}$ in patients with renal cancer. Tumour Biol, 36: 2121 - 2126.

21. Lindholm, E., Bakhtadze, E., Sjögren, M. and et al. (2006). The $-374 \mathrm{~T} / \mathrm{A}$ polymorphism in the gene encoding RAGE is associated with diabetic nephropathy and retinopathy in type 1 diabetic patients. Diabetologia., 49(11): $2745-2755$.

22. Schenk, S., Schraml, P., Bendik, I. and Ludwig, C. U. (2001). A novel polymorphism in the promoter of the RAGE gene is associated with non-small cell lung cancer. Lung Cancer, 32(1): $7-12$

23. Kandeel, A., Genedy, M., El-Refai, S. L., Funk, A., Fontanet, A. and Talaat, M. (2015). The prevalence of hepatitis $C$ virus infection in Egypt: implications for future policy on prevention and treatment. Liver Int., 37: 45 53.

24. Ahmad, A. A., Falla, A. M., Duffell, E., Noori, T., Bechini, A., Reintjes, R. and et al. (2018). Estimating the scale of chronic hepatitis $B$ virus infection among migrants in EU/EEA countries. 
BMC Infect. Dis. 18:34. doi: 10.1186/s12879017-2921-8 and perspectives. Gut 2014; 63: $844-855$.

25. Flemming, J. A., Yang, J. D., Vittinghoff, E., Kim, W. R. and Terrault, N. A. (2014). Risk prediction of hepatocellular carcinoma in patients with cirrhosis: the ADRESS-HCC risk model. Cancer, 120: 3485 - 3493.

26. Chuah, Y. K., Basir, R., Talib, H., Tie, T. H. and Nordin, N. (2013). Receptor for advanced glycation end products and its involvement in inflammatory diseases. Int. J. Inflam., 2013: $403-460$.

27. Shih-Chi, S. u., Ming-Ju, H., Ying-Erh, C., WenLang, F., Chao-Bin, Y. and Shun-Fa, Y. (2015). Effects of RAGE Gene Polymorphisms on the Risk and Progression of Hepatocellular Carcinoma. Medicine, 94(34): e1396.

28. Pan, H., Niu, W., He, L. and et al. (2008) Contributory role of five common polymorphisms of RAGE and APE1 genes in lung cancer amongHan Chinese. PloS One. 8: e69018.

29. Su, S., Chien, M., Lin, C. and et al. (2015). RAGE gene polymorphism and environmental factor in the risk of oral cancer. J. Dent. Res., 94: $403-411$.
30. Zhang, S., Hou, X., Zi, S. and et al. (2013). Polymorphisms of receptor for advanced glycation end products and risk of epithelial ovarian cancer in Chinese patients. Cell Physiol. Biochem., 31: 525 - 531.

31. Pan, H., He, L., Wang, B. and et al. (2014). The relationship between RAGE gene four common polymorphisms and breast cancer risk in northeastern Han Chinese. Sci. Rep., 4: 43 - 55.

32. Hyogo, H. and Yamagishi, S. (2008). Advanced glycation end products (AGEs) and their involvement in liver disease. Curr. Pharm. Des., 14: $969 \quad$ - $972 . \quad$ doi: $10.2174 / 138161208784139701$.

33. Yamagishi, S. and Matsui, T. (2010). Soluble form of a receptor for advanced glycation end products (sRAGE) as a biomarker. Front Biosci., 2: $1184-1195$.

34. Xie, J., Mendez, J. D., Mendez-Valenzuela, V. and et al. (2013). Cellular signaling of the receptor for advanced glycation end products (RAGE). Cell Signal, m 25: 2185 - 2197. 